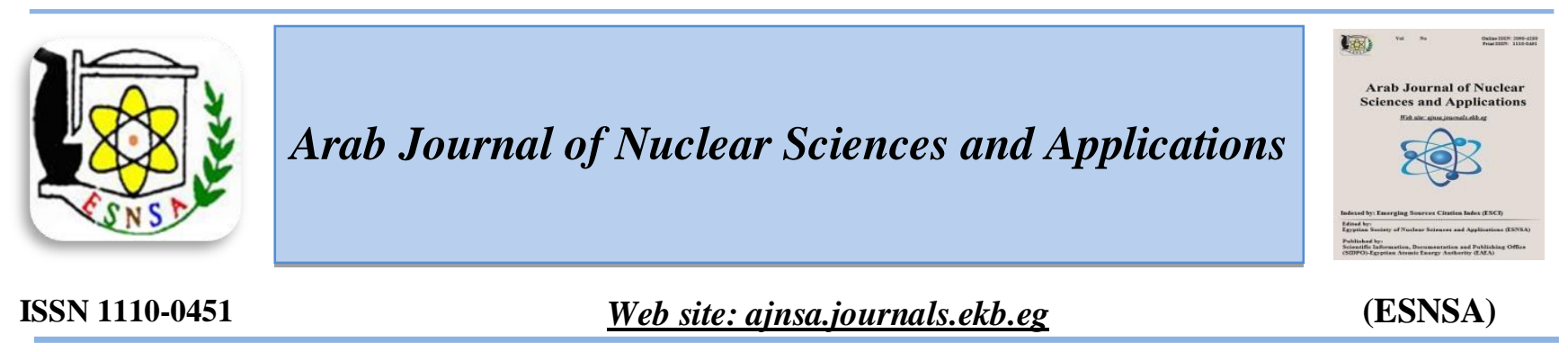

\title{
CPRD Supplied with Native Scintillator for Radon Gas Detection
}

\author{
Ayman Mohamed Abdelmoaty Abdalla ${ }^{\text {a,b* }}$ \\ ${ }^{a}$ Department of Physics, College of Science and Arts, Najran University, Najran, Saudi Arabia \\ ${ }^{b}$ Promising Centre for Sensors and Electronic Devices (PCSED), Najran University, Najran, Saudi Arabia
}

Received $18^{\text {th }}$ Oct. 2018 For neutron detection and radioactive gas sensing, it is greatly beneficial to detect alpha ( $\alpha$ ) particles and Accepted $8^{\text {th }}$ May 2019 gamma rays. In the present work, continuous passive radon detector (CPRD) has been constructed with native $\mathrm{ZnS}$; AgCl scintillator. The detector has been supplied with highly efficient native nano particles scintillator for detection of $\alpha$ particles. One of the features of this scintillator, the energy resolution is comparable with or even better than commercial $\mathrm{ZnS}$ (Ag) scintillator. This study provides an alternative for the fabrication the native scintillator in the absence of costly scintillator available in the market. Moreover, results of scintillation characteristics, along with physical properties of the scintillator, are addressed and thoroughly discussed. For calibration, radon calibration system with dual radon monitor has been constructed in Najran University, Saudi Arabia. The experimental sensitivity of the passive CPRD cell for radon gas detection was constant with well-known data already published in the literatures. Radon emission from a natural sample has been measured by the fabricated CPRD cell.

Keywords: Radon gas detection, Calibration chamber, Sensitivity; ZnS, AgCl scintillator

\section{Introduction}

Radon is an odorless and colorless radioactive gas of a half-life 3.8 days. Beside the natural radioactivity of the gas, Radon is an inert gas, so it is very difficult to react with other materials. The density of Radon is greater than the density of earth atmosphere. The main sources of indoor radon are rocks and ground water [1]. Radon is the decay product of uranium and thorium which are present in the earth's crust. There are three isotopes of radon ${ }^{219} \mathrm{Rn},{ }^{220} \mathrm{Rn}$ and ${ }^{222} \mathrm{Rn}[2]$. For the general public, the highest contribution to the annual dose come from natural sources, from these sources, Radon and his decay products are responsible for a worldwide significant increase of annual dose. In the US radon and Thoron are responsible for approximately $37 \%$ of the exposure received by the human per year. It is well known that, the unreasonable exposure of radiation is dangerous besides, its effects on human health.
These effects include lung cancer, gastrointestinal syndrome, skin injury, hematopoietic damage and even death [3]. So, the developing of a simple and sensitive method for radon gas and radiation detection is rather necessary not only for the normal utilization of ionizing radiation, but also for public safety. Several methods have been used for Radon and radiation detection, this involves solid state nuclear track detector (SSNTD), Lucas cell (LSC), ionization chamber, charcoal canister and scintillation detector [4-5]. The Lucas scintillation cell has been used all over the world for estimation of Radon concentration for long time. Vandilla and Taysum have devised the cell [6]. The cell has been modified by optimizing the volume by others [7-9]. There are two types of Radon cell (active and passive cell). When Radon gas enter the cell, alpha $(\alpha)$ particles from radon or its daughters strike the scintillator and a light pulse will be emanated. In AB-6 and AB-5 Radon

Corresponding author: aymanabdalla62@hotmail.com

DOI: 10.21608 /ajnsa.2019.6631.1152

(C) Scientific Information, Documentation and Publishing Office (SIDPO)-EAEA 
monitors, the photomultiplier tube which is built in the radon monitor will convert this pulse to an electrical signal. Both $\mathrm{AB}-5$ and $\mathrm{AB}-6$ radon monitor use active and passive radon cell. The mechanism of detection by the monitor depends up on the scintillation process. One of the most important wide band gaps II-VI semiconductor is Zinc sulfide. For a long time, $\mathrm{ZnS}$ has been the host material for the most important scintillator. It has been used in different fields, for example optoelectronic, photoelectric and luminescent devices [10-13]. $\mathrm{ZnS}$ doped with $\mathrm{Cu}^{2+}, \mathrm{Mn}^{2+}$ and $\mathrm{Ag}^{+}$etc. is widely used as analytical reagent, coating the Lucas cell, paint and opaque glass due to its fluorescence properties [12]. Also, the $\mathrm{ZnS}$ : Ag scintillator has also been used for a long time in neutron, $\alpha$ particles and radon detection. Various methods have been used for preparing $\mathrm{ZnS}$ powders, for fabrication $\mathrm{ZnS}$ scintillator with good optical properties, the hydrothermal method, colloidal processing and wet chemical process methods can be used [14-16]. Lin and co-workers fabricated $\mathrm{ZnS}$ : Ag by a chemical technique. They found that doping of the $\mathrm{ZnS}$ with $\mathrm{Ag}+$ resulted in impurity levels between the valence (VB) and conduction band (CB). The transition of electrons between these levels resulted in the blue emission [17]. Another research group has studied the effect of activation temperature on the optical and the structure characteristics of $\mathrm{ZnS}$. It was found that the activated $\mathrm{ZnS}$ nano-particles at low temperatures $\left(\leq 550{ }^{\circ} \mathrm{C}\right)$ have a pure cubic phase, while a small amount of hexagonal structure appear in specimens activated at temperatures $\geq 700{ }^{\circ} \mathrm{C}$. At the same time, the $\mathrm{ZnS}$ scintillator that was sintered at $1020{ }^{\circ} \mathrm{C}$ using the nanoparticles activated at $750{ }^{\circ} \mathrm{C}$ clear dense microstructure, with increase in the transmittance in the wavelength range $6.0-12 \mu \mathrm{m}$ [18]. In the recent published paper, the $\mathrm{ZnS}$ : Ag nano-particles have been prepared by hydrothermal method, the radiation detection application in the field of radon detection and characterizations of these nanostructures have been investigated by Lin et al. [17]. Results of preparation and optimization of $\mathrm{ZnS}$ : Ag nano-particles, along with optical and structural estimation, are discussed and also addressed thoroughly. PMT counts and the flounces of $\alpha$ particle have been investigated for ZnS: Ag material, with a strong linear relationship between the two parameters (count\& flounce) has been achieved. The registration detection efficiency of 610A Lucas cell painted with the prepared $\mathrm{ZnS}$ : Ag samples has been obtained, but the efficiency of the cell is $1.5 \%$, this may be attributed to the wavelength of the emission light not matching with the photomultiplier tube [19]. To the best of our knowledge, there are many methods for preparing $\mathrm{ZnS}$ scintillators but the wave length of the emission of these nanoparticles is not matching with the photomultiplier tube (450 $\mathrm{nm}$ ) which work with $\mathrm{AB}-6 \mathrm{~A}$ radon monitor. In the present study, $\mathrm{ZnS}$ nanoparticles were fabricated via a hydrothermal technique, after that $\mathrm{ZnS}$ powder was activated with $\mathrm{Ag}+$ and $\mathrm{Cl}^{-}$ions at $960^{\circ} \mathrm{C}$. Moreover, the $\mathrm{ZnS}$ scintillator synthesized in this project showed high photoluminescence (PL) emission in the blue region $(454 \mathrm{~nm})$ and has been used in blue optical instruments specially radiation detection.

\section{Experimental \\ Preparation}

In this work, a Teflon-lined autoclave $(150 \mathrm{ml}$ capacity), has been used to prepare Zinc sulfide $(\mathrm{ZnS})$ activated with silver $(\mathrm{Ag})$ in a typical reaction process, $(7.68 \mathrm{~g})$ zinc acetate dehydrate $\left(\mathrm{Zn}\left(\mathrm{CH}_{3} \mathrm{COO}\right)_{2} \cdot 2 \mathrm{H}_{2} \mathrm{O}\right)$ and $(4.34 \mathrm{~g})$ sodium thiosulfate pent hydrate $\left(\mathrm{Na}_{2} \mathrm{O}_{3} \mathrm{~S}_{2} .5 \mathrm{H}_{2} \mathrm{O}\right)$ has been dissolved in $(100 \mathrm{ml})$ distilled water. The solution including both $\mathrm{Zn}$ and $\mathrm{S}$ sources has been prepared under continuous stirring in the presence of high pure nitrogen gas. After the purification process, the resulting solution has been heated for 180 minutes in a Teflon-lined autoclave at $493 \mathrm{~K}$. Finally, after the prepared powder has been washed with distilled water and ethanol, respectively, and then dried at $338 \mathrm{~K}$ for 0.5 -day, spherical nano-precipitates were obtained. Finally, the powder has been activated by $\mathrm{Ag}^{+}$and $\mathrm{Cl}^{-}$ions. The activation process has been carried out by an environmental oven working under flow of high purity nitrogen $(99.9999 \%)$.

\section{Characterization}

In this work, the phase structure of the sample has been investigated by $\mathrm{X}$ - ray diffraction spectrometer (Model: PAN analytical Xpert Pro), with magnification of $30000 X$. The field emission scanning electron microscope (FESEM) (Model, JSM-7600F, Japan) has been used to examine the morphology of the samples. The PL emission spectrum has been studied by Hitachi F-7000 fluoresce spectrophotometer. After finding the best 
optical emission, the only body of continues passive radon detector (CPRD) has been coated with the prepared native $\mathrm{ZnS}: \mathrm{Ag}, \mathrm{Cl}$ scintillator. The cell is aluminum metal cylinder; the cell can be attached to the radon monitor by ABA adaptor. $\mathrm{ZnS}$ : Ag scintillator (GL47/N-C2) obtained from phosphor technology; UK was used for the comparative study in this work. The average diameter of Phosphor-type GL47/N-C2 is $8 \mu \mathrm{m}$ (www.crystals.saint-gobain.com) [20]. The pulse high spectrum (PHS) studied at Nara institute of science and technology, Japan, the details of the experiment set up for PHS measurements has been published in a previous publication [21].

\section{Specification of CPRD cell}

Figure (1) shows the structure of the CPRD cell. The CPRD cell is a metal cylinder having the following dimensions: Diameter: $6 \mathrm{~cm}$, height: 15 $\mathrm{cm}$ and Weight: 140. The first face includes, four opining to allow radon to enter the detection volume, a piece of sponge to prevent the entry of dust (3), metal cover (4) to fix the sponge and the screen (3). After optimizing the emission spectrum of the prepared scintillator, the inter body of the CPRD cell has been painted by the scintillator by the help of supper 77, multi-purpose adhesive. After that the powder was sprinkled on the paint until it saturated.

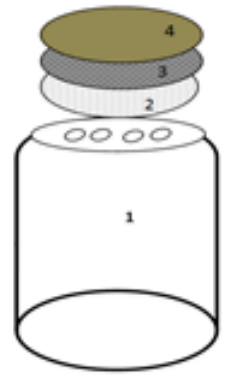

Figure (1): Depicts the constriction of the cell body

\section{Results and Discussion}

\section{Synthesis and activation}

After a series of experimental work, the best conditions for preparing $\mathrm{ZnS}$ has been chosen. Figure (2) shows the SEM images of the asprepared $\mathrm{ZnS}$ sample (A) and the standard sample (B). It is clear that the prepared sample has spherical shape. It is known that, the spherical shape of the host material ZnS play an important rule during the activation process. For enhancing the PL emission and increasing the degree of crystallinity, the prepared $\mathrm{ZnS}$ sample was activated with the activator $\left(\mathrm{Ag}^{+}\right)$and the coactivator $\left(\mathrm{Cl}^{-}\right)$at $960{ }^{\circ} \mathrm{C}$. Figure (3) illustrates the SEM images for the activated sample. It is clear from Figure (3) that the activated sample has no regular shape with nanoscale size. Comparison of Figs. (2 and 3) shows that the spherical $\mathrm{ZnS}$ particles are made up of nanoparticles of zinc sulfide.
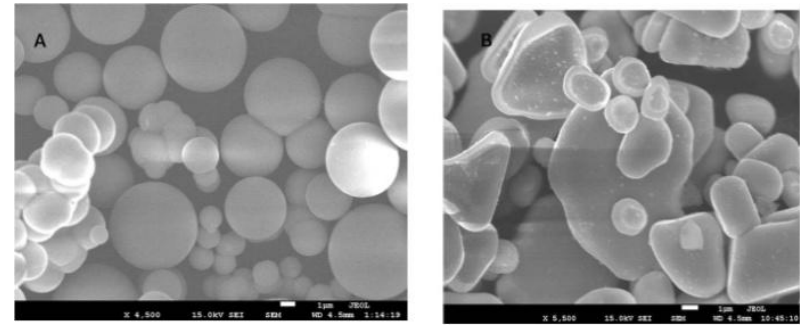

Figure (2): The SEM image of (A) prepared sample, and (B) stander sample

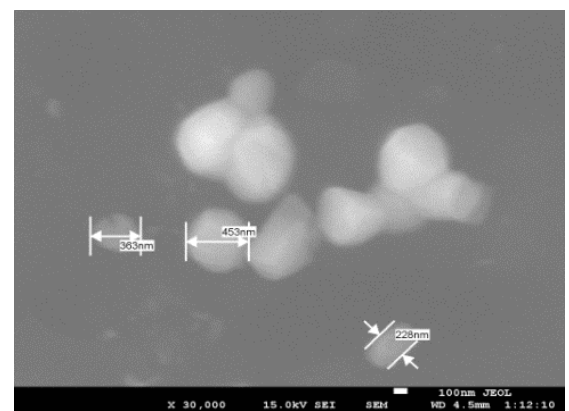

Figure (3): The SEM image of prepared sample after activation

The XRD analysis

Figure (4) shows the X-ray diffraction pattern of the activated $\mathrm{ZnS} ; \mathrm{Ag}, \mathrm{Cl}$ nanopowders. Three sharp diffraction peaks have been dedicated. The lattice planes of (111), (220) and (311) are responsible for the three peaks. The peaks confirm the formation of the cubic phase zinc blended structure (JCPDS No. 05-0566) [22], The ZnS phase was well formed in these samples as shown in Fig (4). Although the hexagonal cubic phase transition temperature is $1020{ }^{\circ} \mathrm{C}$, the reflections for the hexagonal wurtzite structure were observed [23]. Compared to the previous study, X-ray diffraction (XRD) patterns show that the activation at $960{ }^{\circ} \mathrm{C}$ improves the degree of the crystallinity of the scintillator [19]. However, neither peaks for activator nor the co activator have been observed. This is a confirmation of the immersion of activator and the co activator atoms in the unit cell.

\section{Photoluminescence properties}

Figure (5) illustrates the luminescence spectra of $\mathrm{ZnS}: \mathrm{Ag}, \mathrm{Cl}$ measured at different concentrations 
of $\mathrm{AgNO}_{3}$. The PL peak position located at $454 \mathrm{~nm}$ of the nanostructure gradually increases with AgNO3 concentrations. Also, the PL emission spectra of $\mathrm{ZnS}$ scintillator doped with $\mathrm{Ag}+$ and $\mathrm{Cl}-$ showed no shift compared to the undoped $\mathrm{ZnS}$ scintillator. The optimum value of the PL emission spectrum intensity of $\mathrm{ZnS}$ activated with $\mathrm{Ag}$ was obtained for $0.3 \mathrm{mg} / \mathrm{g}$ value of activator. Also, the symmetry in the emission spectrum curve around the wavelength of $454 \mathrm{~nm}$ has been detected and no other emission peaks has been observed. The single emission peak may be attributed to the impurity levels. In addition, $\mathrm{Ag}$ concentration $\leq$ $0.3 \mathrm{mg} / \mathrm{g}$, the intensity of the emission spectrum of $\mathrm{ZnS}$ activated with $\mathrm{Ag}$ is higher than that of the pristine $\mathrm{ZnS}$ scintillator. This means that in this range of activator concentration, the crystalline quality and structural order increase after $\mathrm{Ag}$ doping. With increasing the Ag concentration more than $0.3 \mathrm{mg} / \mathrm{g}$, the emission spectrum decreases which leads to an increase in the non-radiative recombination [24]. Figure (6) demonstrates the trend of changes of the PL area under the peak of the $\mathrm{ZnS}$ nanostructures. The most notable feature of Figure (6) is that PL intensities gradually increase with the concentration of $\mathrm{Ag}$ from 0.1 to $0.3 \mathrm{mg}$. There is an abrupt decrease in the area under the peak from 0.0 .3 to $0.7 \mathrm{mg}$. The cause of the decreasing the emission spectrum with increasing the concentration of the activator may be attributed to the nonradioactive Auger effect is thought to play an important role [25]. It is clear from Figure (7) that the standard sample has larger emission spectrum than the prepared one. This may be attributed to, the scattering caused by the refractive index difference between the hexagonal and cubic matrix phases, which lead to the difference in the transmittance of light in both of hexagonal wurtzite and cubic phase [26]. This may be the main reason for the apparent difference in the emission spectrum of the prepared and the standard material.

\section{$U V$-visible analysis}

UV-visible absorption spectroscopy is an effective technique to investigate the optical properties of semiconducting materials. Figure (8) demonstrates the UV-visible spectra (in transmutation mode) of the as prepared $\mathrm{ZnS}$ activated with $\mathrm{Ag}+$ and $\mathrm{Cl}$ ions $(0.3 \mathrm{mg})$ and the standard sample. At a characteristic wave length of $450 \mathrm{~nm}$, the transmittance of the stander sample is 1.3 time the transmittance of the prepared sample, in a good agreement with PL measurements.

It can be seen from Figure (8) that the prepared sample is quite transparent in the visible region. The transmittance values of the prepared and standard sample are a maximum at around $220 \mathrm{~nm}$. The transmittance peak is blue shifted with respect to the standard sample due to a small particle size. This shift could be associated with the particle size and quantum confinement effect. Also, it can seen that, $\mathrm{ZnS} ; \mathrm{AgCl}$ scintillator that was activated using $\mathrm{ZnS}$ nano-particles at $960{ }^{\circ} \mathrm{C}$ exhibited low transmittance, because of the difference in the refractive index of cubic and hexagonal phase in good agreement with XRD results. A recent study clarifies that the existence of the hexagonal wurtzite phase besides the cubic matrix phases reduces transmittance of $\mathrm{ZnS}$ because of the birefringence of the hexagonal structure and the scattering of the emission spectrum caused by the difference in the refractive index between the hexagonal and cubic phase [26]. Also, the prepared sample has a higher concentration of $\mathrm{Zn}$ more than $\mathrm{S}$, and this may be another reason for the difference in the transmittance.

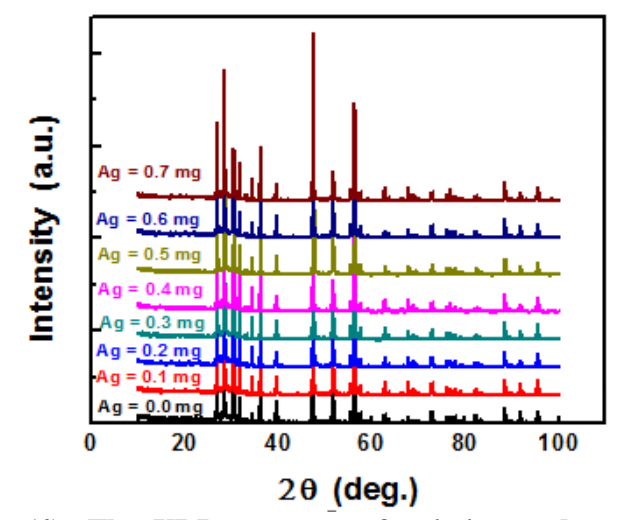

Figure (4): The XRD patterns of pristine and activated ZnS samples

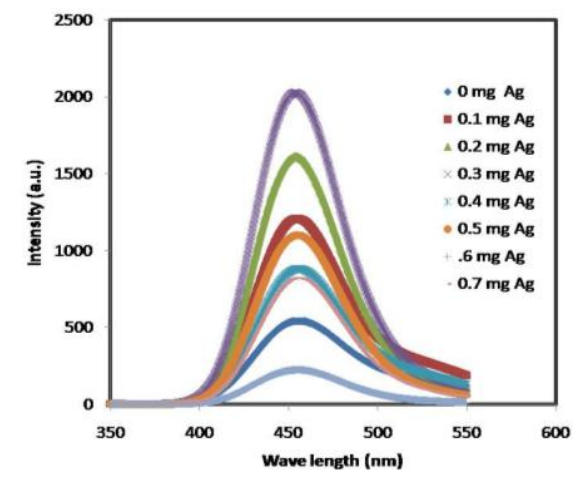

Figure (5): Luminescence spectra of $\mathrm{ZnS}$ : $\mathrm{Ag}, \mathrm{Cl}$ measured at the different concentration of $\mathrm{AgNO3}$ 


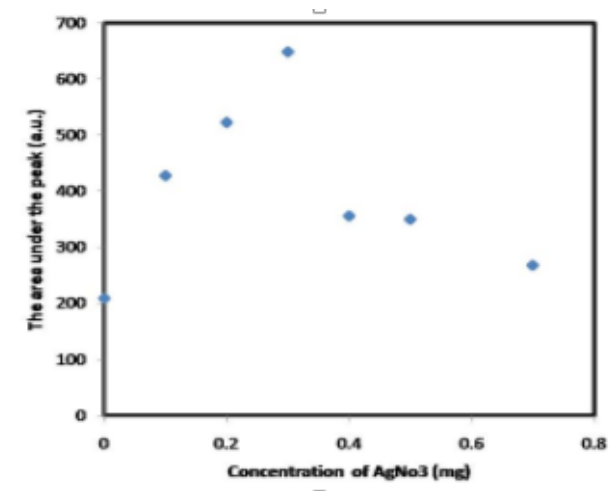

Figure (6): The area under the peak of luminescence spectra of $\mathrm{ZnS}$ : $\mathrm{Ag}, \mathrm{Cl}$ as a function of the concentration of $\mathrm{AgNO}_{3}$

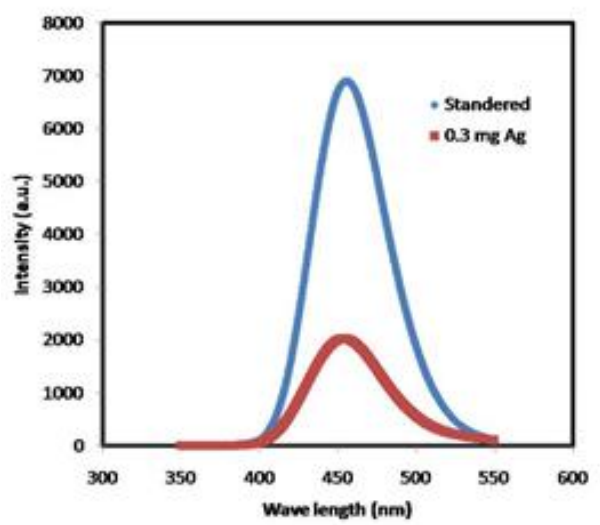

Figure (7): Luminescence spectra of the prepared $\mathrm{ZnS}$ : $\mathrm{Ag}, \mathrm{Cl}$ and the stander sample

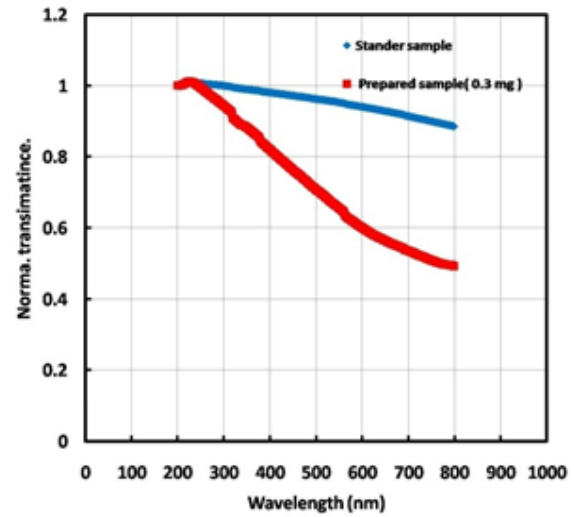

Figure (8): Transmittance spectra of the stander sample and as prepared sample

\section{Pulse high spectrum of 241Am source}

To investigate the effect of particle size up on the energy resolution, the energy spectrum of $241 \mathrm{Am}$ alpha particle source has been measured using $\mathrm{ZnS}$; Ag naoparticles (without firing) and the stander sample. Figure (9) shows the Pulse height spectra of $241 \mathrm{Am} \alpha$-particles and $60 \mathrm{KeV} \gamma$ Rays measured by using the standered and the $\mathrm{ZnS} ; \mathrm{Ag}$ sample. It is clear that the standard sample has Arab J. Nucl. Sci. \& Applic. Vol. 52, No. 3 (2019) high light yield emission compared to the prepared sample, in good agreement with PL measurements, but the prepared sample has batter resolution. This may be attributed to the small size of the prepared sample. For enhancing the scintillation characteristics of the prepared sample, the $\mathrm{ZnS}$ has been prepared by (1:1) molar ratio, after that the prepared powder has been activated with $\mathrm{Ag}^{+}$and $\mathrm{Cl}^{-}$ions. The $\mathrm{ZnS} ; \mathrm{AgCl}$ scintillator has been used to paint the continues passive radon detector (CPRD). More details about the preparation and characteristics are under publication.

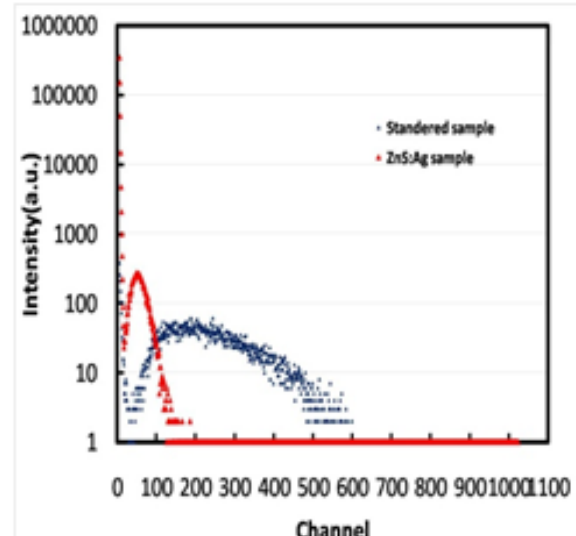

Figure (9): The pulse height spectra of 241 Am $\alpha$-particles and $60 \mathrm{KeV} \gamma$ Rays measured by using standered and prepared samples $(\mathrm{ZnS}$; $\mathrm{Ag})$ without firing

\section{Calibration and application}

To determine the sensitivity of CPRD cell and its environmental applications, a radon calibration system with known radon activity must be constructed. Figure (10) illustrates the radon calibration system with dual radon monitor. This chamber can be used for studying the effect of radon concentration, humidity, temperature and flow rate on the sensitivity of the detector. The radon chamber is made of metallic cylindrical barrel, having two openings in the high face of the container with a cover, diameter of $15 \mathrm{~cm}$ and 5 $\mathrm{cm}$ respectively to insert or remove the samples and other equipment. The steel container has two gas tight valves to control the flow of radon gas through the system. According to the literature; Granit contains a considerable amount of natural radioactive material $[27,28]$. In this project, the alternatives and temporary natural radon source that contains $10 \mathrm{Kg}$ of Granit from Najran city was used. Also, polyethylene membrane was used as filter to prevent ${ }^{220} \mathrm{Rn} \&{ }^{219} \mathrm{Rn}$ radon isotopes from diffusing into the active volume off the radon detector [28]. An active standered Lucas cell (610A) attached with radon monitor (AB6A) was 
used to evaluate the activity level of radon during the experiment. The cell has Mating Connectors: Swagelok B-QC4-S-4HC.These two mating connector's help to connect the cell to the rest of the system, through rubber tubes. The active ( 610A) Lucas cell has an effective volume of 154 $\mathrm{ml}$, detection sensitivity of $0.729 \mathrm{cpm} / \mathrm{pCi} / \mathrm{L}$ and registration efficiency 71.098 [29]. One connector on the active cell (610A) was connected with the outlet tube from the radon source through two porous polyethylene filters and the drying column. In order to dry the air inside the radon irradiation system a drying column has been used, the two porous polyethylene filters have been used to prevent radon daughters from interring the detection system. The inlet tube of the programmable pump of the AB6A active radon monitor has been connected with Lucas cell (610A) by one Swagelok, the outlet tube of the programmable pump of the AB6A active radon monitor was connected to the flow meter and the AB-5 radon Monitor, as shown in Figure 10. The outlet of the AB-5 monitor has been connected with the radon source through the second valve. By using a flow adjust control, The AB6A active radon monitor with built in programmable pump have been controlled the flow rate of air mixed with Radon gas inside the system. At the end of each experiment, the radon specific activity and/or the CPM were stored in the memory of AB6A and AB-5 Monitor each hour. The data can be printed by using PPT-1printer. At the same time, the data can be transferred to the computer through the DA2005 interface. Also, the data can be saved in the computer. Also, AB-6 incorporates advanced technology for humidity and temperature determination. It includes user-friendly features for enhanced performance and versatility. One benefit of this calibration system beside radon monitoring, both of temperature and humidity can be measured continuously.

Before calibration, The system was well closed and the radon concentration was measured for 33 days. The standard active cell has been used to evaluate the radon concentration in the chamber. Figure (11) demonstrates the variation of the activity of radon concentration as a function of time inside the radon calibration system. From this figure, one can notice the radon concentration reach maximum value $120 \mathrm{~Bq} / \mathrm{m} 3$ after 26 days. After measuring the concentration of radon inside the chamber by the two devices, The (CPRD cell) is then connected with $\mathrm{AB}-5$ monitor and the monitor is operated by the counting mode. After one day of work, the average count per mint has been achieved. Using equation 1, the sensitivity of the cell is defined by the concentration information and the average count per minute. the AB-5 use the following general formula in continues method [29].

$C_{R n}=\frac{N C P M}{S}$

where $C_{R n}$ is the specific activity of radon gas, NCPM is the total count per minute after subtracting the background rate, and $\mathrm{S}$ is the counting sensitivity value. From the experimental study, it is found the sensitivity of the local CPRD is $0.03535 \mathrm{CPM} / \mathrm{Bq} / \mathrm{m}^{3}$.

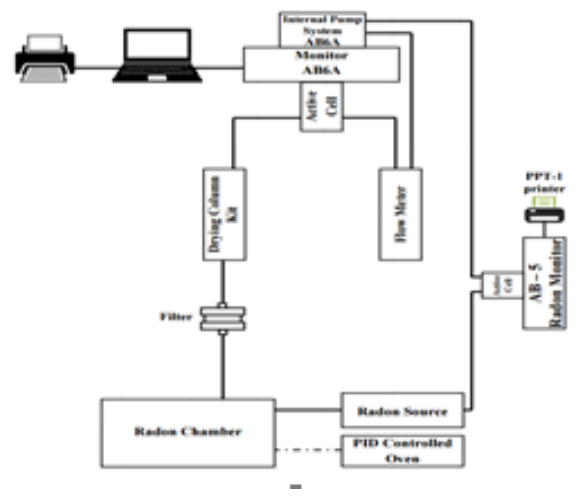

Figure (10): Radon calibration system with dual radon monitor

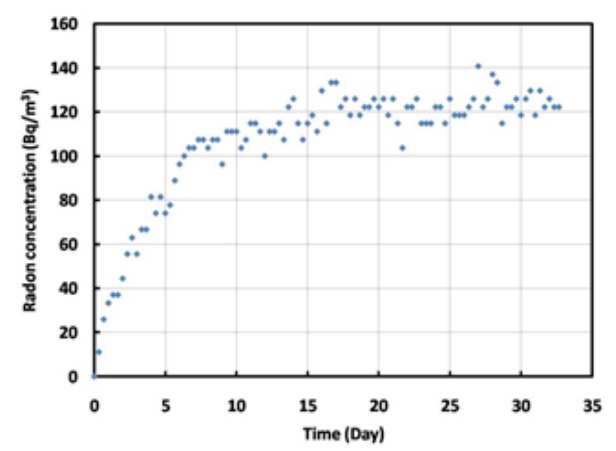

Figure (11) Radon concentration inside the radon calibration system at Najran University, Saudi Arabia

To verify the calibration process carried out in Najran University. The CPRD cell has been calibrated in calibration division, pylon company, Ottawa, Canada. The exposure time and the concentration of radon inside the Canada radon chamber is 70 hour and $4491.35 \mathrm{~Bq} / \mathrm{m}^{3}$ respectively. Table (1) lists the results of calibration. It is found that, the sensitivity of the 
CPRD cell is $0.0351 \pm 0.0002 \mathrm{cpm} / \mathrm{Bq} / \mathrm{m}^{3}$. There is a considerable agreement between the sensitivity value of the local CPRD cell and the CPRD standard cell. So, the CPRD cell coated with the native scintillator provides a convenient means for determining the specific activity of radon gas. The local CPRD cell is manufactured with a highly sensitive native nanoparticle scintillator doped with $\mathrm{Ag}$ and $\mathrm{Cl}$ ions for radon detection. The prepared scintillator is insensitive to gamma radiation. For this reason, it is possible to achieve the low background essential for measuring low radon concentrations. To test the performance of our local CPRD cell, the radon concentration level inside the radon calibration system at Najran University, has been determined again by $\mathrm{AB}-5$ monitor coupled with the local CPRD cell. Figure (12) shows the radon concentration inside the chamber as a function of time. It obvious that the average radon concentration is $121 \mathrm{~Bq} / \mathrm{m}^{3}$, and there is a considerable agreement between the radon concentration measured by our local CPRD cell and that measured with the standard cell, as shown in Figs. (11 and 12).

Table (1): Parameter of KACST Radon CPRD cell and CPRD stander Radon cell. See Appendix (1)

\begin{tabular}{ccc}
\hline Cell name & Detector Sensitivity & Background \\
\hline $\begin{array}{c}\text { CPRD stander } \\
\text { cell }\end{array}$ & $\begin{array}{c}0.04054 \pm 0.0002 \\
\mathrm{cpm} / \mathrm{Bq} / \mathrm{m}^{3}\end{array}$ & $0.75 \mathrm{cpm}$ \\
CPRD cell & $0.0351 \pm 0.0002 \mathrm{cpm} / \mathrm{Bq} / \mathrm{m}^{3}$ & $0.84 \mathrm{cpm}$
\end{tabular}

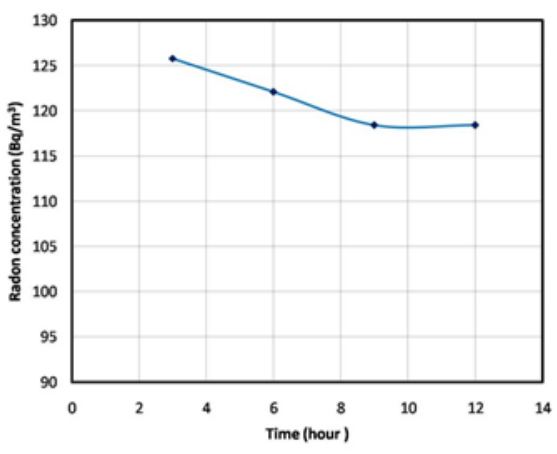

Figure (12): Radon concentration inside the radon calibration system measured with local CPRD cell

\section{Conclusion}

In this work, a continuous passive radon detector (CPRD) has been constructed with a high efficiency native scintillator. The scintillator has blue emission at $454 \mathrm{~nm}$. The sensitivity of the cell is $1.28 \mathrm{CPM} / \mathrm{pCi} / \mathrm{l}$. There is a considerable agreement between the sensitivity value of the Arab J. Nucl. Sci. \& Applic. Vol. 52, No. 3 (2019)
CPRD cell developed in Najran University and the corresponding sensitivity measured in the Calibration Division, Pylon Company, Canada. The local radon calibration chamber showed efficiency in the process of calibrating CPRD Radon detector and its environmental application. To enhance the scintillation properties of the local scintillator, preparation of the native scintillator, with cubic single phase is in progress.

\section{Acknowledgment}

General Administration of Research Grants - King Abdulaziz City for Science and Technology, the kingdom of Saudi Arabia, supported this project (grant number: AT-35-199). The author would like to acknowledge the General Administration of Research Grants, King Abdulaziz City for Science and Technology for the financial support.

\section{References}

1-Jianping.,W. Pengfei. C ,Zhongwei. C, Banghua.Y ,Chunshan. Z , Bing. J and Xiaochuan.W. (2018) Experimental study on radon exhalation characteristics of coal samples under varying gas pressures., Results in Physics (10), 1006-1014.

2-Reddy, D.V., Nagabhushanam, P., Sukhija. B.S and Rajender, Reddy.G. (2010) Continuous radon monitoring in soil gas towards earthquake precursory studies in basaltic region., Radiation Measurements (45), 935-942).

3-Vahabi, S.M., Zafarghandi, M.S., Ghasemi, M., Alipoor A. and Shahvar, A. (2013)A prototype of an ionization chamber for gamma radiation beams of 60Co: experimental and monte carlo preliminary results, Radiat. Meas. (59), 284-287.

4- Dong, X.B., F. Hu, Liu Z.T., Zhang G.X. and Zhang D.Q. (2015) A fluorescent turn-on low dose detection of gamma-radiation based on aggregation-induced emission, Chem. Commun. (510, 3892-3895.

5-El-Sammane ,H., Arafa ,W, and Abdalla ,A. (2002) Temperature and humidity consideration for calculating airborne $222 \mathrm{Rn}$ using activated charcoal canisters. Health Phys. (83) 97-105.

6-Vandilla, M.A and Taysum, D.H. (1955) Scintillation counters for assay of radon gas. Nucleonics (13), 68.

7-Kristan, J., and Kobal, I. (1973) A modified scintillation cell for determination of radon in uranium mine atmosphere. Health Phys. (24), 103-104. 
8- Lucas ,H.F. (1957) Improved low level alpha scintillation counter for radon. Rev. Sci. Instrum. (28), 680.

9-Poncela, L.S Q., Fernandex, P.L., Sainz, C., Arteche, J. Arozamena, J.G., and A.C George. (2003) An improved scintillation cell for radon measurements., Nucl. Instr. Meth. Phys. Res; A (512), 606.

10-wang, H., Chen, Z., Cheng, Q., and Yuan, L. (2009) Solvothermal synthesis and optical properties of single-crystal $\mathrm{ZnS}$ nanorods, J. Alloys. Compd. (478), 872-875.

11- Iranmanesh,P., Saeednia, S., and Nourzpoor, M. (2015) Characterization of $\mathrm{ZnS}$ nanoparticles synthesized by co-precipitation method, Chin. Phy. B. (24), 046104.

12- Ramavath, P., Biswas, P., Johnson,R., Reddy, G.J., and Laxminarayana ,P. (2014) Hot isostatic pressing of $\mathrm{ZnS}$ powder and CVD $\mathrm{ZnS}$ ceramics: comparative evaluation of physico chemical, microstructural and transmission properties, Trans. Ind. Ceram. Soc. (73), 299-302.

13-Martyshkin, D.V., Fedorov,V.V., Kim, C., Moskalev, I.S., and Mirov,S.B. (2010) Mid-IR random lasing of $\mathrm{Cr}$-doped $\mathrm{ZnS}$ nanocrystals, J. Opt. (12) 024005.

14-Molaei,M., Molaei, A. Khezripour ,R., and Karimipour, M. (2014)nanocrystals (NCs) using a rapid microwave irradiation method and investigation of the effect of copper $(\mathrm{Cu})$ doping on the optical properties. Appl. Surf. Sci; (317), 236.

15-Karimipour,M., Moradi ,N., and Molaei M. (2017) Strong NIR luminescent Ag2S@ZnS core-shells synthesized by a novel one pot pulsed microwave irradiation,J. Lumin. (182), 91-97.

16-Chlique,C., Merdrignac-Conanec ,O.,Hakmeh,N., Zhang X, and Adam,J.L.(2013)Transparent ZnS ceramics by sintering of high purity monodisperse nanopowders, J. Am.Ceram. Soc. 96 (10) 30703074.

17-Lin ,K.B., and Su,Y.H. (2013)Photoluminescence of $\mathrm{Cu}: \mathrm{ZnS}, \mathrm{Ag}: \mathrm{ZnS}$ and $\mathrm{Au}: \mathrm{ZnS}$ nanoparticles applied in Bio-LED, Appl. Phys. B; (113), 351.

18-Tak Lee .Ku., Boo-Hyun Choi , Jong-Un Woo, Jeong-Su Kang, Jong-Hoo Paik , Byoung-Uck Chu and Sahn Nahm. (2018) Microstructural and optical properties of the $\mathrm{ZnS}$ ceramics sintered by vacuum hot-pressing using hydrothermally synthesized ZnS powders., Journal of the European Ceramic Society (38) ,4237-4244.
19-Abdalla M.A, Ali M.A and Al-Jarallah.M.(2018) Characterization and radiation detection application of $\mathrm{ZnS}(\mathrm{Ag})$ nanoparticles., Physica B: Condensed Matter (550), 235-243.

20-http://www.phosphortechnology.com/products/crt.

21-Abdalla A.M. (2018) Detection capabilities of alpha particles and gamma rays using DAMADC scintillator, Nuclear Inst. and Methods in Physics Research; A( 901), 99.

22-Kamal Bera ., Satyajit Saha and Paresh Chandra Jana. (2018) Investigation of Structural and Electrical properties of $\mathrm{ZnS}$ and $\mathrm{Mn}$ doped $\mathrm{ZnS}$ nanoparticle., Materials Today: Proceedings (5) 6321-6328.

23-Ku-Tak Lee , Boo-Hyun Choi , Jong-Un Woo, Jeong-Su Kang, Jong-Hoo Paik , Byoung-Uck Chu and Sahn Nahm.(2018) Microstructural and optical properties of the $\mathrm{ZnS}$ ceramics sintered by vacuum hot-pressing using hydrothermally synthesized ZnS powders. Journal of the European Ceramic Society (38), 4237-4244.

24-Jrad,A., Naffouti, W., Ben Nasr ,T., and TurkiKamoun, ,N. (2016) Comprehensive optical studies on Ga-doped $\mathrm{ZnS}$ thin films synthesized by chemical bath deposition, J. Lumin. (173) ,135-140.

25-Raue,R., Shiki,M., Matsukiyo,H., Toyama H., and Yamamoto.H.(1994)Saturation of $\mathrm{ZnS}: \mathrm{Ag}, \mathrm{Al}$ under cathode ray excitation. J. Appl. Phys. (75) ,481-488.

26- Chen,Y. L., Zhang, J., Zhang, P., Liu, T., Zhou, H., Zhang, D., Gong, D., Tang and Shen, D. (2015)Fabrication of transparent $\mathrm{ZnS}$ ceramic by optimizing the heating rate in spark plasma sintering process, Opt. Mater. (50), 36-39.

27-Al-Azmi.D(2009) The use of soil gas as radon source in radon chambers. Radiat. Meas. (44) ,306-310.

28- Abdalla .A.M., and Al-Hajry, A. (2015) Radon irradiation chamber and its applications. Nucl. Instru.Meth. Phys. Res. A (786), 78-82.

29- Pylon Electronics Inc. model AB-5 Rev. 5 June .(1993) 21 